\title{
Reverse logistics network design: a holistic life cycle approach
}

\author{
Joanna Daaboul', Julien Le Duigou, Diana Penciuc and Benoît Eynard
}

\author{
* Correspondence: \\ joanna.daaboul@utc.fr \\ Department of Mechanical Systems \\ Engineering, Université de \\ Technologie de Compiègne, UMR \\ CNRS 7337 Roberval, rue du Dr \\ Schweitzer, CS60319, 60203 \\ Compiègne Cedex, France
}

\begin{abstract}
When aiming for a more sustainable world, enterprises such as aircraft and automobile industries are highly interested in lightweight components and solutions. Among these solutions are aluminum wrought alloys that offer high potentials for dramatic weight reduction of structural parts. Nevertheless, the production of virgin aluminum is highly energy consuming. Major energy reduction may be achieved if recycled aluminum is used. The aim of the European project SuPLight is to address new industrial models for sustainable lightweight solutions - with recycling in high-end structural components based on wrought alloys. This article addresses the issue of designing the reverse logistics network assuring the needed volume of recycled aluminum for the production of L-shaped front lower control arms for personal cars. It details the developed method and demonstrator for designing a reverse logistics network based on a life cycle assessment.
\end{abstract}

Keywords: Reversed logistics design; LCA; Wrought aluminum

\section{Introduction}

Until recently, reverse logistics (RL) was not given a great deal of attention in organizations. Actually, implementing reverse logistics programs to reduce, reuse, and recycle wastes from distribution and other processes generates tangible and intangible value and can lead to better corporate image [1]. Its main drivers are legislations and directives, consumer awareness, and social responsibilities towards the environment [2-4]. Another motivating driver of reverse logistics is economic factors. Reverse logistics can generate profits by reselling valuable components or products [5]. Reverse logistics is of high importance for aluminum-based products, since the production of virgin aluminum is highly energy consuming [6]. It is also proven that remanufacturing is beneficial for many industries in general [7] and for the automobile industry specifically [8].

Reverse logistics operations and chains they support are significantly more complex than traditional manufacturing supply chains [9-11]. Therefore, and similar to how companies develop efficient logistics processes for new goods, it is necessary to plan operations for returned goods, taking into consideration that the processes are most probably quite different from those defined for forward distribution [12]. Reverse logistics is not a symmetric picture of forward distribution [13] and requires different management and planning approaches. For example, it is difficult, in the case of RL, to estimate supply-related parameters such as the unit operational costs directly from

(C) 2014 Daaboul et al.; licensee Springer. This is an Open Access article distributed under the terms of the Creative Commons Attribution License (http://creativecommons.org/licenses/by/4.0), which permits unrestricted use, distribution, and reproduction in any medium, provided the original work is properly credited. 
reported statistical data. The design of a reverse logistics network should be based on an integrated approach [14].

The aim of this article is to design an effective reverse logistics network for the L-shaped front lower control arms (FLCA) (Figure 1) for personal cars [15] within the SuPLight project which is a multidisciplinary research project, combining physics at the atomic scale level, metallurgy, continuum mechanics, structural mechanics, optimization algorithms, tolerance analysis, life cycle analysis, manufacturing, and business modeling. The project addresses new industrial models for sustainable lightweight solutions - with $75 \%$ recycling in high-end structural components based on aluminum wrought alloys.

The designed reverse logistics network has the following characteristics:

1. The reverse logistics network should be environmentally friendly as much as possible. Thus, the reverse logistics design method should integrate environmental impact as decision criteria.

2. The different facilities (collection locations, remanufacturing facilities, etc.) are not necessarily owned by one company.

3. The reverse flow has different sources and might have depending on these sources different disposal routes (reselling, remanufacturing, recycling, etc.).

\section{Background and related works}

A reverse logistics network is formed by four main activities: gatekeeping, collection, sorting, and recovery (disposal) [16]. These are shown in Figure 2.

Many recent works propose models and methods for the design of a reverse logistics network. These mainly propose the use of mathematical programming, and more precisely mixed-integer linear programming models are used [17]. According to the recent literature review in [17], the only objectives considered in reverse logistics or forward/ reverse network design are cost, profit, responsiveness (service level), source balance,

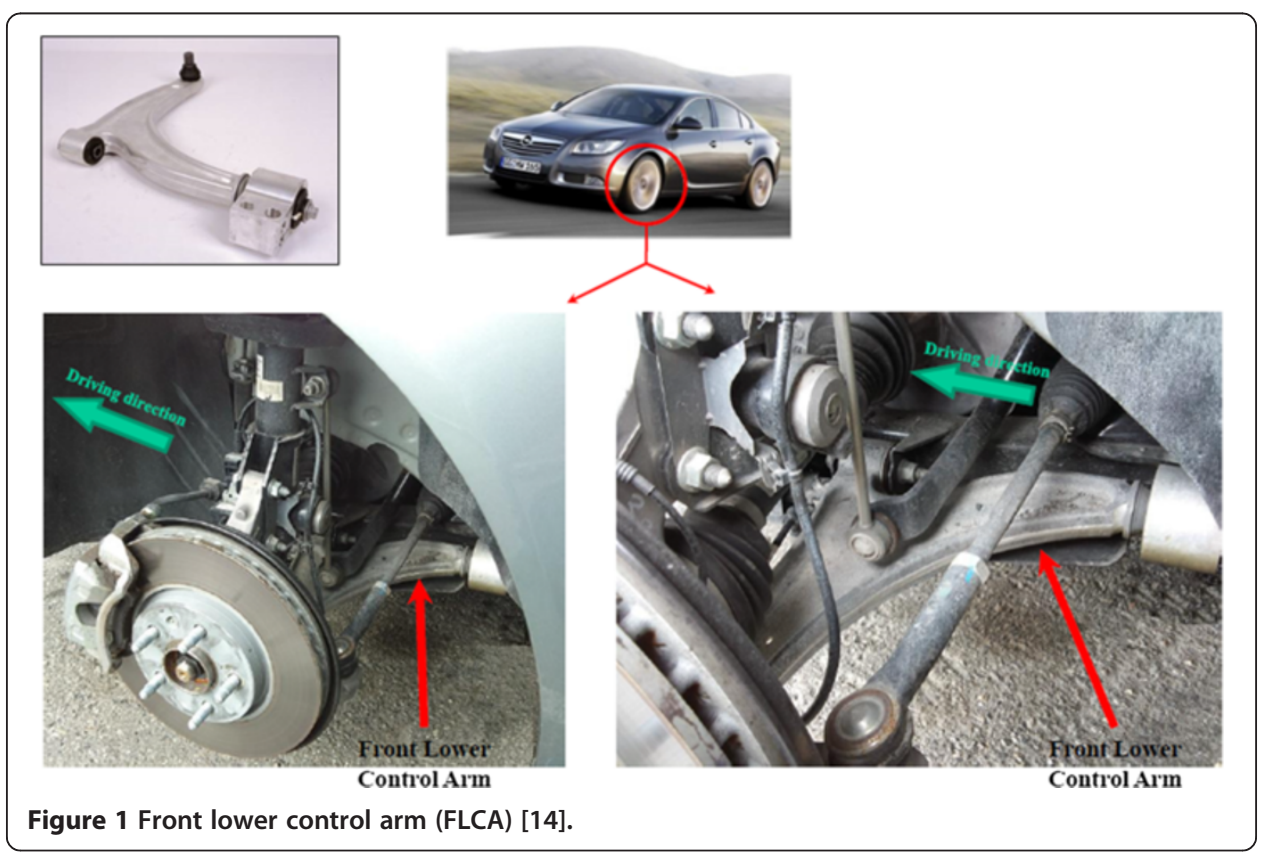




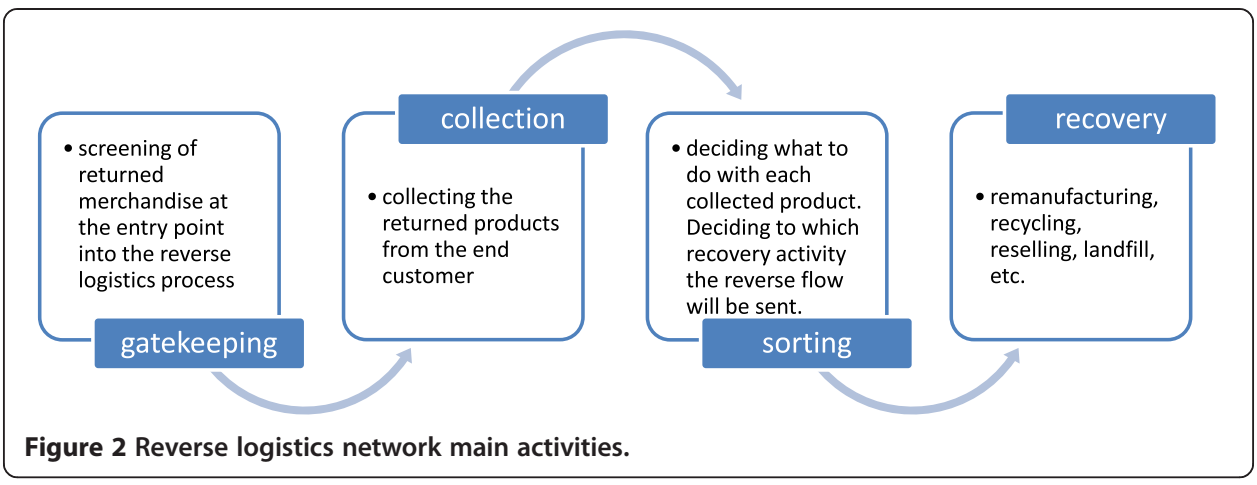

and quality. The most considered decision criterion is the total cost of the network [18-22], followed by the service level [23]. Zhou and Wang [24] propose a generic model for reverse logistics design considering only costs as decision criteria. Lee and Dong [25] propose a two-stage stochastic programming model for multi-period reverse logistics network design with the different investment and operational costs as the main decision criterion. Lambert et al. [26] consider the environmental regulations as a constraint to their decision model but not as decision criteria. Cardoso et al. [27] proposed a mixed-integer linear programming model for supply chain planning including reverse logistics activities. Yet they consider the expected net present value (ENPV) as the decision criterion. In this case study and research work, the environmental impact of the network is an important design factor; therefore, it should be considered as a main decision criterion in the design of reverse logistics network. This means considering not only the environmental impact of transportation activities, but also the remanufacturing and recycling activities.

The main decisions of the proposed models in the literature are location/allocation of facilities and transportation values [18-23]. Most of these models consider the network design problem with collection, sorting, and recovery (disposal) facilities owned by one company which is collecting the reverse flow and reusing it. This is not always the case. Reverse logistics networks include not only facilities owned by the company itself, but also facilities owned by other partners in the network. This means that designing the best reverse logistics network includes three main decisions: 1) making/buying, 2) supplier selection, and 3) location/allocation of facilities.

These three decisions should be made while taking into consideration the environmental performance of the reverse logistics network. This means integrating environmental indicators as decision criteria.

Few works considered the recycling option of the recovery step [20,28]. Most works found in the literature consider the remanufacturing option [18,19,21-23]. In this case study, the interest is in using recycled aluminum. Thus, the main considered recovery activity is recycling. This means that the reverse flow will probably have different sources, which might not all have the same recovery route (related recycling activities).

\section{A framework for the design of reverse logistics Network design method}

Since the main aim of this project is to be more sustainable and more precisely to have a better environmental performance, a life cycle approach seems adequate to analyze 
the performance of the chosen network. It permits assessing the environmental performance of the reverse logistics network alone and also its impact on the whole life cycle assessment of the product. This permits integrating the environmental performance of the network as a decision criterion for its design. The proposed method is formed by five main steps presented in Figure 3 .

\section{Step 1: Context definition}

In this step, the company and the product(s) are described. The constraints of the company are listed as well as its preference for outsourcing/insourcing reverse logisticsrelated activities.

\section{Step 2: Parameter definition}

The parameter definition, as shown in Figure 4, consists of identifying the different roles in a reverse logistics network, the responsibilities and activities per role, the requirements for these activities, and the performance indicators per requirement per activity. Four roles were identified:

1. The collector: responsible for the gatekeeping and collection activities

2. The sorter: responsible for sorting activities

3. The recoverer: responsible for recovery activities (recycling, remanufacturing, landfill, etc.)

4. The end collector of reverse flow: the user of the final recovered reverse flow.

The same partner may have more than one role, and different partners might have the same role. For example, the end collector of a reverse flow might also collect the

1

- Context definition

\begin{tabular}{|l|l|}
\hline - Definition of the main RL parameters \\
- Definition of the different roles in a RL network \\
- Definition of main activities in a RL network \\
- Definition of gatekeeping activities \\
- Definition of collection activities \\
- Definition of sorting activities \\
- Definition of recovery (disposing) activities \\
- Identification of possible companies per role \\
- Definition of performance indicators
\end{tabular}

Figure 3 Proposed method for reverse logistics network design. 


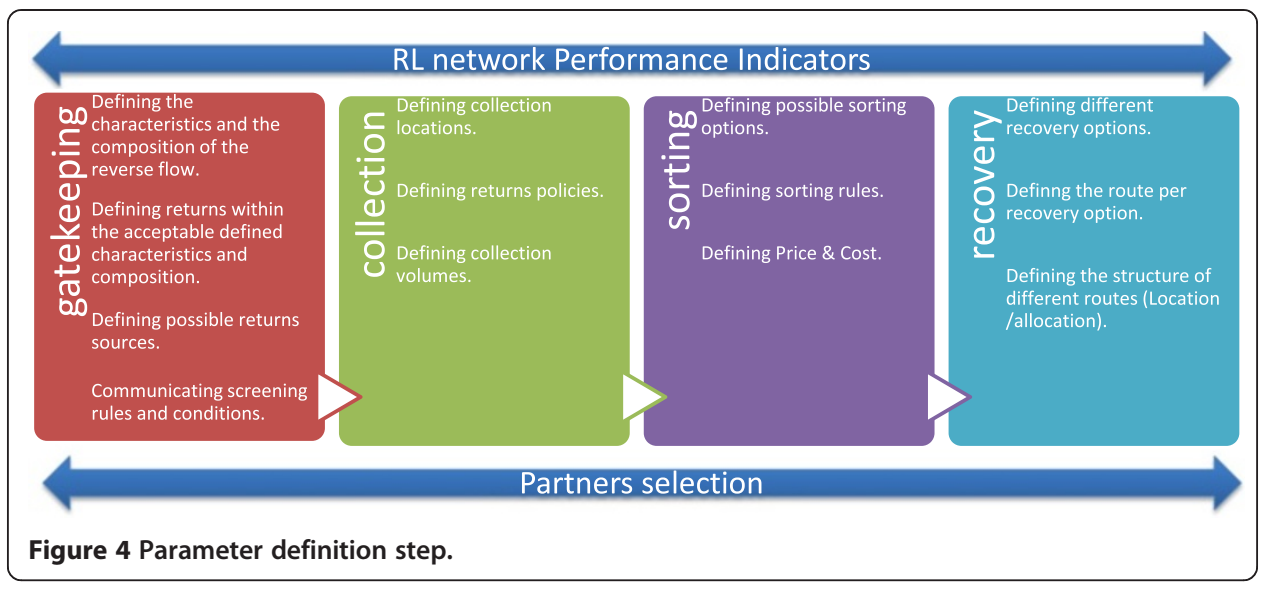

returns, and a sorter might also recycle or remanufacture the reverse flow. One partner may have all roles. In this case, the same company owns the entire reverse network.

The requirements per activity are case dependent. Most of them depend on the type of the product. The recycling processes for example differ based on the product type, whereas the general performance indicators are the same no matter the product type.

Concerning the performance indicators, these are:

- Total cost of the network including cost of transportation, facilities, purchasing, activities, and stock: This is the most used reverse logistics performance indicator in the literature (see the 'Background and related works' section).

- Recycling rate: This indicator reflects the service level of the entire network. It reflects the percentage of recycled material for the product using the recovered reverse flow.

- Life cycle assessment-related indicators: These indicators permit evaluating the environmental impact of the reverse logistics network. Considering the environmental performance of the reverse logistics network is the main goal of this work. The most used life cycle assessment (LCA) indicators are climate change (or carbon footprint of product), energy-related indicators, chemicals used, PFC/GHG emissions, fresh water consumption, and use of renewable/nonrenewable energy.

The above presented indicators are decision criteria for the design of the reverse logistics network. Other indicators are needed for the supplier selection decision. According to [29], the most used criteria for the supplier selection decision are price, deliver on time, quality, equipment and capability, geographic location, technical capability, and finally management and organization. To these criteria, the environmentrelated indicator is added: the green processes. This indicator reflects whether the processes used are environmentally friendly or not. This indicator is of outmost importance for the sorting and recycling activities where the environmental impact depends on the technology used.

In this step, candidate companies for playing one or more roles in the reverse logistics network are also defined. For each company, a description sheet is filled containing information on the company, performance indicators, and constraints, such as the minimum quantity of reverse flow and replenishment lead time. 


\section{Step 3: Scenario definition}

The scenario definition is achieved by the expert user in one of two ways:

1. Defining any reverse logistics network scenario, by choosing for each role one or more companies as well as the quantity of reverse flow and then by choosing the routes between these companies.

2. Defining the reverse logistics network step by step, using decision criteria per role. In this case, and for every role, the user may ask to identify the best company based on many decision criteria, identified in step 2. This option is based on the analytical hierarchy process (AHP). AHP is the most used decision support system for supplier selection [30]. This technique which was developed by Thomas L. Saaty [31] relies on the expertise of the user in order to generate the weights of attributes. It is based on the comparison of pairs of options and criteria. It has found widespread application in decision-making problems, involving multiple criteria in systems of many levels [32]. Its main advantages are:

- Consideration of non-tangible subjective attributes

- Ability to structure a complex multi-criteria, multi-person, and multi-period hierarchical problem

- Capability to investigate each level of the hierarchy separately and to combine the results as the analysis progresses

- Binary comparison of elements (alternatives, criteria, and sub-criteria)

- Availability of IT support.

The steps that need to be followed in this option are:

1. Fill for every potential partner the measured performance for all decision criteria identified previously.

2. Fill the criteria comparison matrix for all criteria identified in the 'Background and related works' section.

3. Choose a specific role of the reverse logistics network. The design may be made in a forward or backward manner. This means the allocation of partner per role may be realized by starting at the end of the network or at its beginning.

4. Choose a specific type of reverse flow.

5. Identify all candidates (company/facility/supplier) for the chosen role.

6. Select the decision (selection) criteria of interest (from the pool of all available criteria).

7. Calculate the weights, using AHP.

8. Rank all candidates, using AHP.

9. Select the candidate ranked first.

10.Allocate order quantities, choose transportation mode, and validate.

The user may choose many scenarios as desired and compare their performance in steps 4 and 5 . In other words, the user may compare on the basis of all environmental and economic criteria the scenarios built with the decision aid option and with any other scenario built by the user alone without any aid of the system. 
Steps 4 and 5: Assessment of reverse logistics scenarios and result analysis

After one or more scenarios are chosen, the different performance indicators are calculated. A comparison between the scenarios is provided.

The evaluation of the reverse logistics network is achieved via life cycle assessment software (SimaPro) [33]. This is possible within the SuPLight project which aims at providing a collaborative platform [34] allowing the communication and exchange of information between different softwares such as the LCA software and the reverse logistics demonstrator.

After the life cycle assessment of the different reverse logistics scenarios is received from the LCA software, a full analysis combing this assessment and the one achieved via the reverse logistics prototype (total cost of the network, quantity of recycled material, etc.) is provided to the user. A comparison of all created reverse logistics scenarios is then delivered to the user.

The AHP method is reused at this stage to identify the best-fitting reverse logistics network.

\section{Reverse logistics prototype (demonstrator)}

The proposed method was the basis of the development of the software prototype. It has been designed with a flexible architecture in order to allow portability and interoperability with any external application. The software prototype implementation is based on the MVC software architecture pattern, using HTML5 and CSS to create the view and for the application logic the JAX-RS Java API for RESTful web services which are controlled by JavaScript (JQuery).

The reverse logistics prototype is focused on reverse logistics scenario definition allowing the user to choose the partners of the reverse logistics network and their roles and visualize them on a map; define reverse logistics routes - a single route is characterized by flow and transportation data (the flow type and the quantity exchanged between two partners, transportation mean and distance); visualize the summary of the created scenario and the final route on the map; display LCA indicators for the current scenario; compare several scenarios on a radar graph based on the indicator value and the total RL cost; use the decision aid system to choose partners based on input criteria; determine recommended quantities for each route; and compute RL indicators for each scenario (total cost of the network, quantity of recycled material, etc.). Google services are used for automatic distance calculation and map display based on data provided by the user. The prototype main page and the route definition interface are presented in Figures 5 and 6, respectively. On the main page, the prototype shows the reverse logistics scenario on a map with a description of the different routes including the node names (companies' names) with the type of reverse flow, quantity of flow, transportation mode, and distance between the two nodes. The different enterprises or facilities chosen for the reverse logistics network are presented on the map. This map is dynamic and shows the chosen facility locations or the chosen suppliers as well as all related costs. This map serves only as a visualization tool for the chosen scenario.

This prototype is not intended for advanced planning of a supply chain such as the advanced planning and scheduling (APS) software. But its main function is to provide a support for decision making in designing a reverse logistics network. Even though the APS software may provide 'What if' analysis, it does not offer a decision aid method 


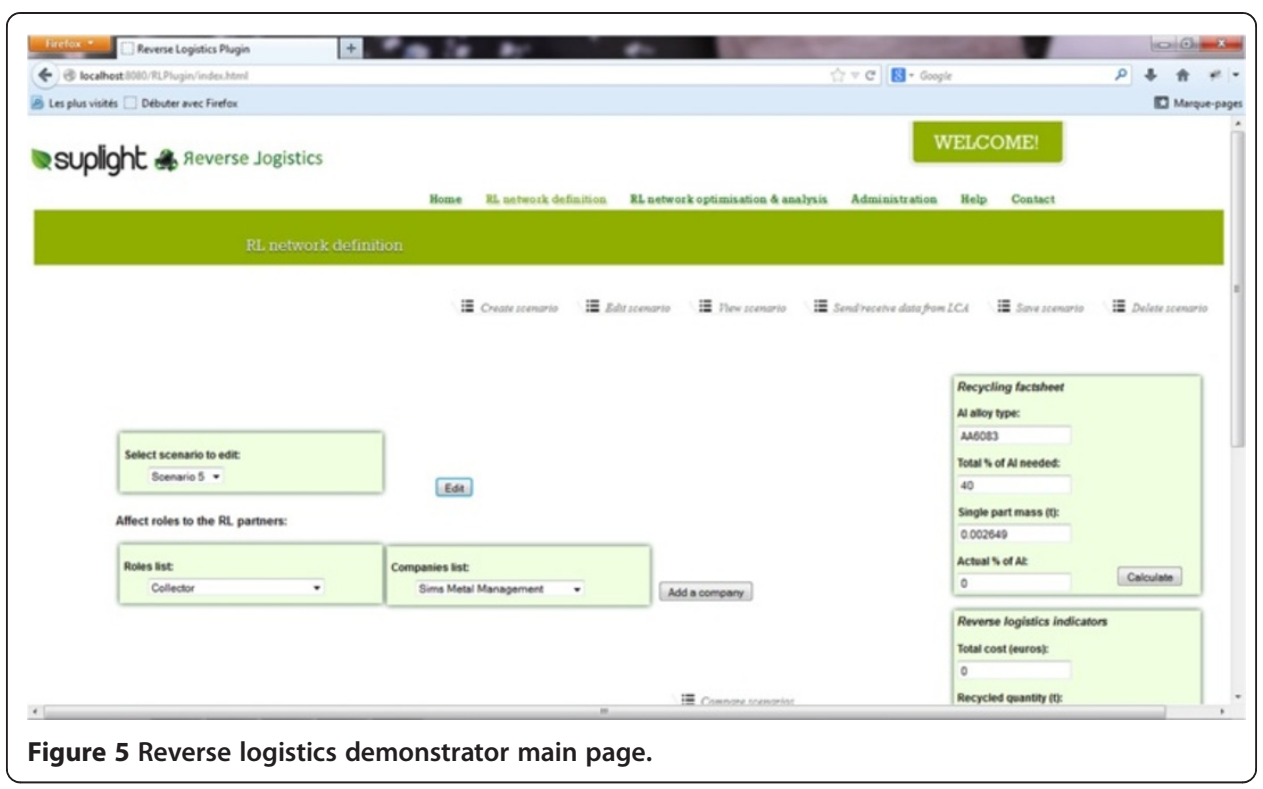

such as AHP nor does it provide the optimal reverse logistics network among all possible scenarios; it permits only to compare between manually created scenarios. The use of the proposed demonstrator does not eliminate the need to use the APS software which is necessary to manage a reverse logistics network. The demonstrator may be considered as a plug-in for the APS software.

\section{Application of the proposed framework to an industrial case study}

\section{Step 1: Context definition}

The case study concerns a front lower control arm of GM Opel Insignia. This component was chosen by Raufoss Technology (RT) as a case study. RT is the end collector of reverse flow in this case study. RT wishes to only have the role of the end collector of reverse flow. This means all other reverse logistics activities are outsourced.

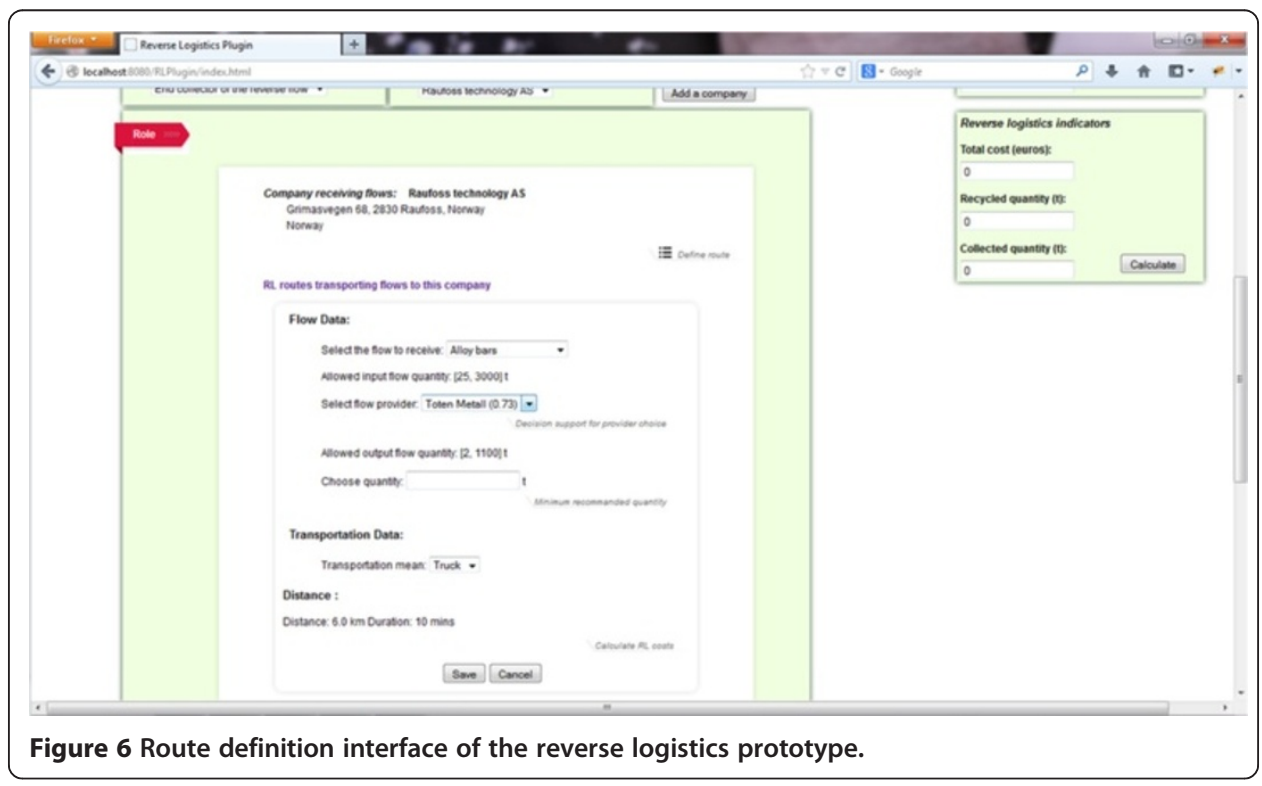


The control arm which is an important part of a vehicle's suspension system consists of a bar used to attach the suspension members to the vehicle's chassis. It is produced from a high-strength wrought aluminum alloy: AA6082. The control arm is produced by hot forging and machining from extruded aluminum billets. Heat treatment is necessary to obtain the necessary strength.

\section{Step 2: Defining reverse logistics parameters Defining the gatekeeping activity}

The acceptable characteristics and chemical compositions are defined as well as possible returns (specific products/alloys) and their sources. These are presented in Table 1.

\section{Defining the collection activity}

Possible collection locations were identified (Table 1). At first, the type of these collection locations was defined. Then, specific enterprises of the identified types were determined.

\section{Defining the sorting and the recovery/treatment activities}

The aluminum recycling industry includes a wide range of processes, which require a wide range of control techniques. These different processes have different environmental performance and produce different qualities of reverse flow. Moreover, they are not all suited for all types of returns containing aluminum. The only recovery option considered in this case study is recycling for acceptable returns. Thus, the sorting activity consists of selecting acceptable returns, shredding it, and separating aluminum alloys

Table 1 Acceptable returns and their sources

\begin{tabular}{|c|c|c|}
\hline Products/alloys & Product/source & Possible collection locations \\
\hline Bumper & Vehicle (dismantling) & $\begin{array}{l}\text { Car scrap yard, automotive dismantlers, } \\
\text { and recyclers }\end{array}$ \\
\hline Wheels & Vehicle (dismantling) & $\begin{array}{l}\text { Car scrap yard, automotive dismantlers, } \\
\text { and recyclers }\end{array}$ \\
\hline Suspension, chassis, etc. & Vehicle (dismantling) & $\begin{array}{l}\text { Car scrap yard, automotive dismantlers, } \\
\text { and recyclers }\end{array}$ \\
\hline $\begin{array}{l}\text { Closures, skin sheet, } \\
\text { and inner stiffness }\end{array}$ & Vehicle (dismantling) & $\begin{array}{l}\text { Car scrap yard, automotive dismantlers, } \\
\text { and recyclers }\end{array}$ \\
\hline Body structure & Vehicle (dismantling) & $\begin{array}{l}\text { Car scrap yard, automotive dismantlers, } \\
\text { and recyclers }\end{array}$ \\
\hline Seats & Vehicle (dismantling) & $\begin{array}{l}\text { Car scrap yard, automotive dismantlers, } \\
\text { and recyclers }\end{array}$ \\
\hline AA3003 & Vehicle (shredding, alloy separation) & Shredding plant \\
\hline AA5754 & Vehicle (shredding, alloy separation) & Shredding plant \\
\hline AA6016 & Vehicle (shredding, alloy separation) & Shredding plant \\
\hline AA6060 & Vehicle (shredding, alloy separation) & Shredding plant \\
\hline Wrought 1 & Vehicle (shredding, alloy separation) & Shredding plant \\
\hline Wrought 2 & Vehicle (shredding, alloy separation) & Shredding plant \\
\hline Siding & Building (demolition) & Demolition contractors \\
\hline Window frames & Building (demolition) & Demolition contractors \\
\hline 3004 corrugating roofing & Building (demolition) & Demolition contractors \\
\hline Foils & Packaging (sorting) & European recycling centers and companies \\
\hline Rigid containers & Packaging (sorting) & European recycling centers and companies \\
\hline Closures & Packaging (sorting) & European recycling centers and companies \\
\hline
\end{tabular}




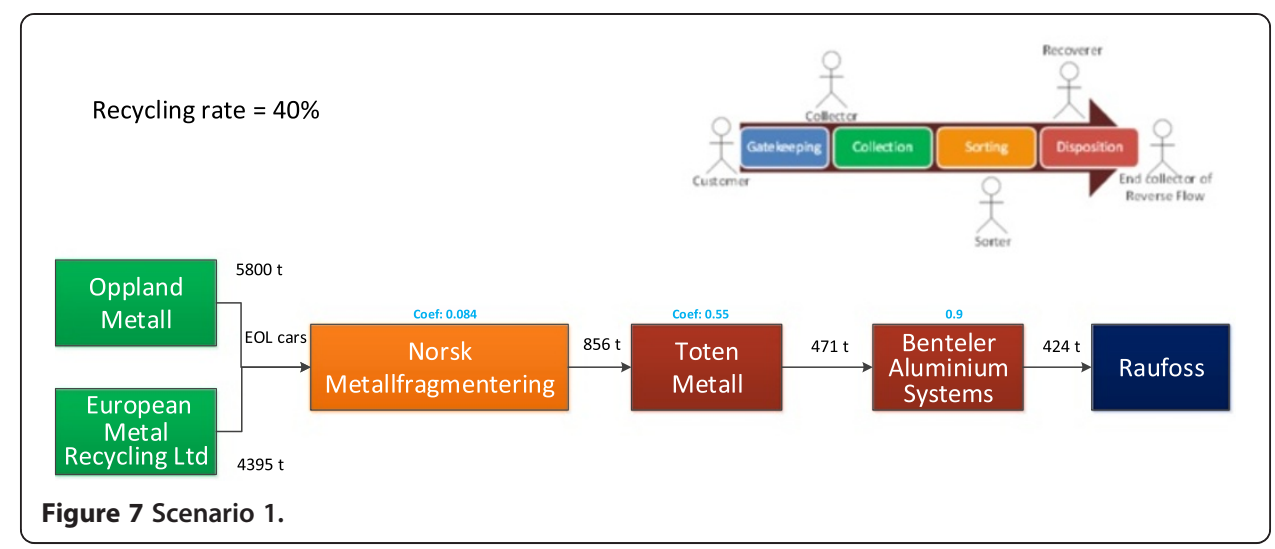

from other materials including other metals. This step will output the necessary scrap that will be used in the recycling activity. In summary, the sorting and recovery activities are the following:

1. Shredding

2. Sorting: electromagnetic separation, eddy-current separation, sink-float, and color sorting/etching

3. Refining: distillation, electrolytic separation, hot crush, unidirectional solidification, and flux separation

4. Remelting

5. Casting aluminum

6. Extrusion.

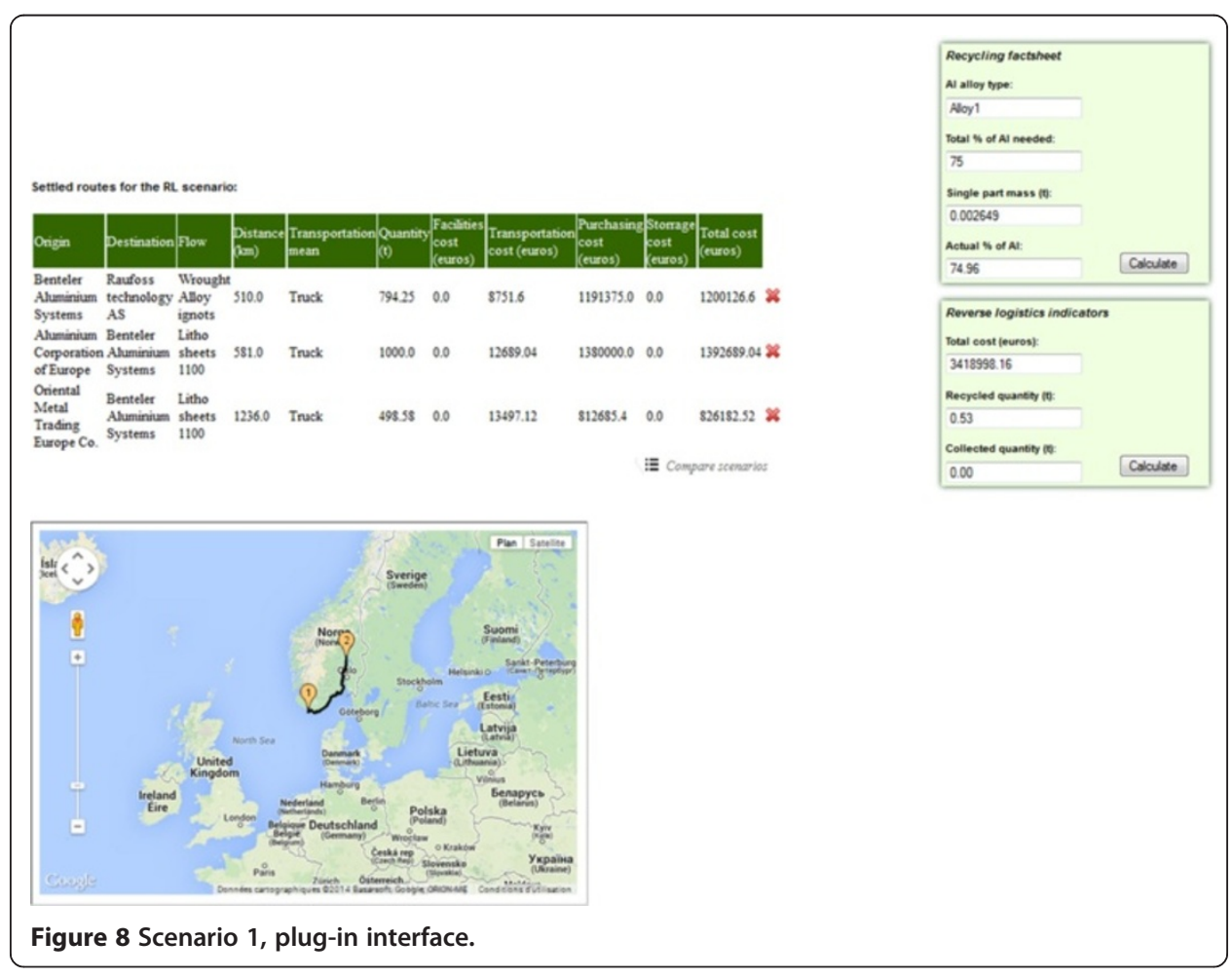




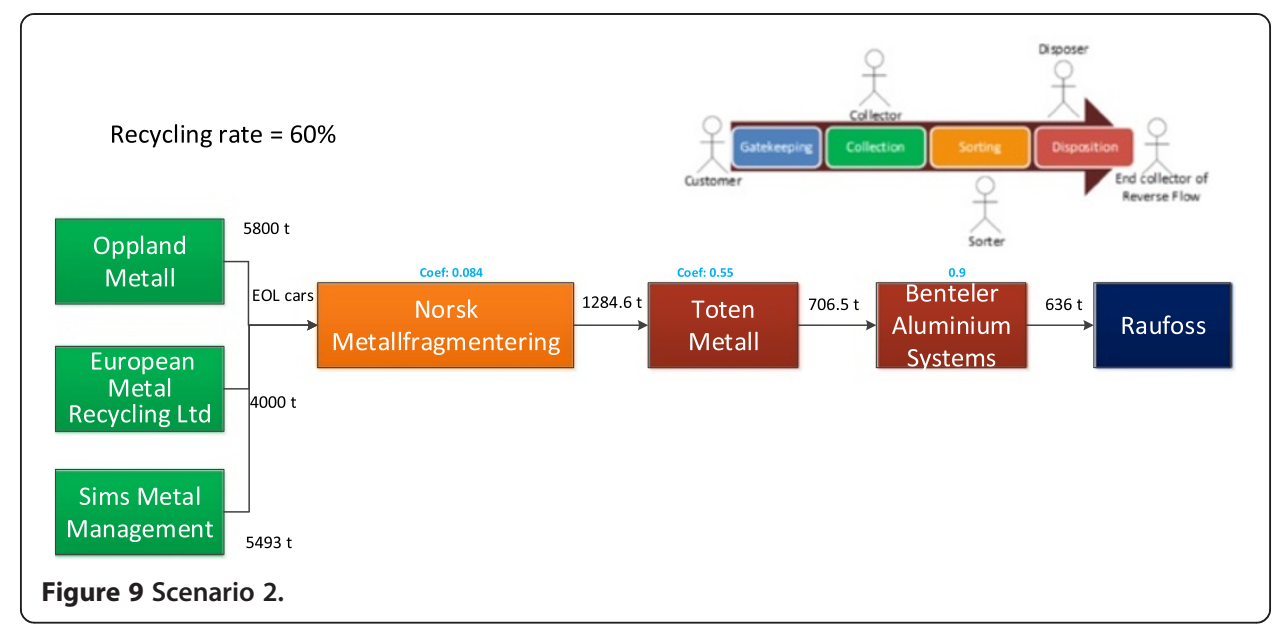

\section{Identifying potential partners}

Potential partners were identified for the three roles: collector, sorter, and recoverer. These and the related collected data are not shown in this article due to confidentiality issues. In total, 20 potential partners were identified.

\section{Step 3: Defining different reverse logistics scenarios}

Using the reverse logistics plug-in, two main RL scenarios were identified. These are presented in Figures 7, 8, 9, and 10. In the figures, a coefficient is indicated for every selected partner. This is equal to the coefficient of output/input. It represents the percentage of the covered input at the end of the activity achieved at this partner. The collector coefficient corresponds to the average percentage of $\mathrm{Al}$ in a car. The coefficient of sorting and recycling activities is recovered from AL recycling literature. The

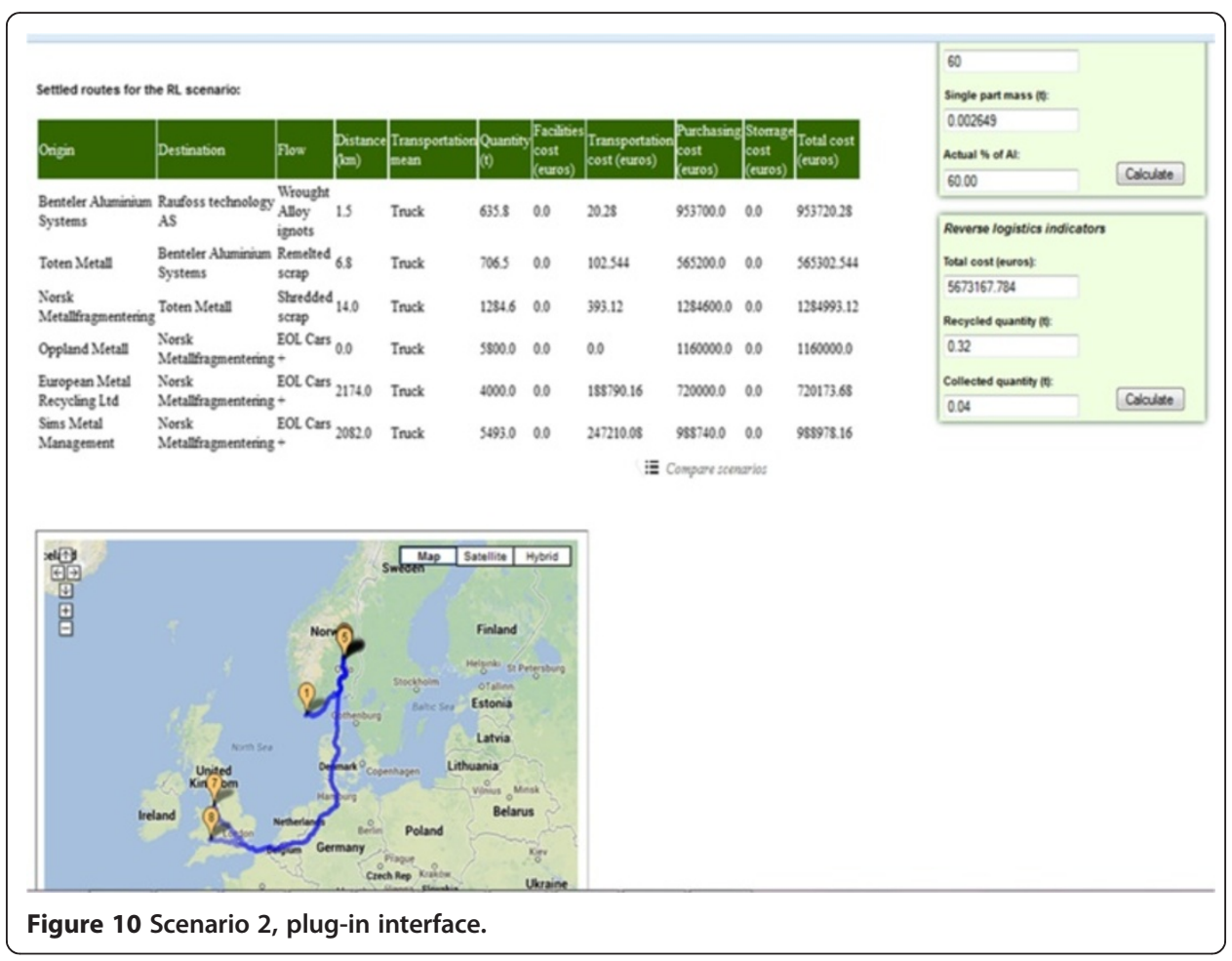


Table 2 Results for the reverse logistics scenarios considering environmental performance for EOL

\begin{tabular}{lllll}
\hline Indicator & Unit & Plug-in & Scenario 1 & Scenario 2 \\
\hline Nonrenewable energy (resources) & $\mathrm{MJ}$ & $\mathrm{LCA}$ & 57.2 & 72.46 \\
Climate change & $\mathrm{kg} \mathrm{CO} \cdot$ eq. & $\mathrm{LCA}$ & 7.74 & 8.66 \\
Fresh water consumption (water withdrawal) & $\mathrm{m}^{3}$ & $\mathrm{LCA}$ & 0.058 & 0.065 \\
Recycling rate & $\%$ & $\mathrm{RL}$ & 40 & 60 \\
Total reverse logistics cost & Euros & $\mathrm{RL}$ & $3,848,108.92$ & $5,673,167.78$ \\
\hline
\end{tabular}

recommended quantity calculated via the plug-in takes into consideration this coefficient. The choice of a partner is made based on different criteria such as the geographical location, the transportation mean, the transportation cost, the quality of the reverse flow, the price of the reverse flow, the order delay, the partner reputation, the partner flexibility, and green processes used. The final criterion is very important since the aim of the designed reverse logistics is to reduce environmental impacts.

\section{Step 4: Assessment of the different reverse logistics scenarios}

Using the reverse logistics plug-in and via its communication with the SuPLight platform, the performance of the designed RL networks is calculated. Considering environmental performance, the user may choose to view the environmental impact of the designed reverse logistics network, either for the end-of-life (EOL) phase or for the whole life cycle. The results presented in Table 2 show the performance of reverse logistics scenarios considering only the EOL phase. Figure 11 compares the environmental impact of reverse logistics scenarios to the baseline scenario which is the current state with $0 \%$ recycled aluminum.

Step 5: Analysis of the assessment results and definition of the best reverse logistics scenario Using the reverse logistics plug-in, scenarios may be compared on a radar graph; the AHP method is used in this step in order to define the best scenario. It permits

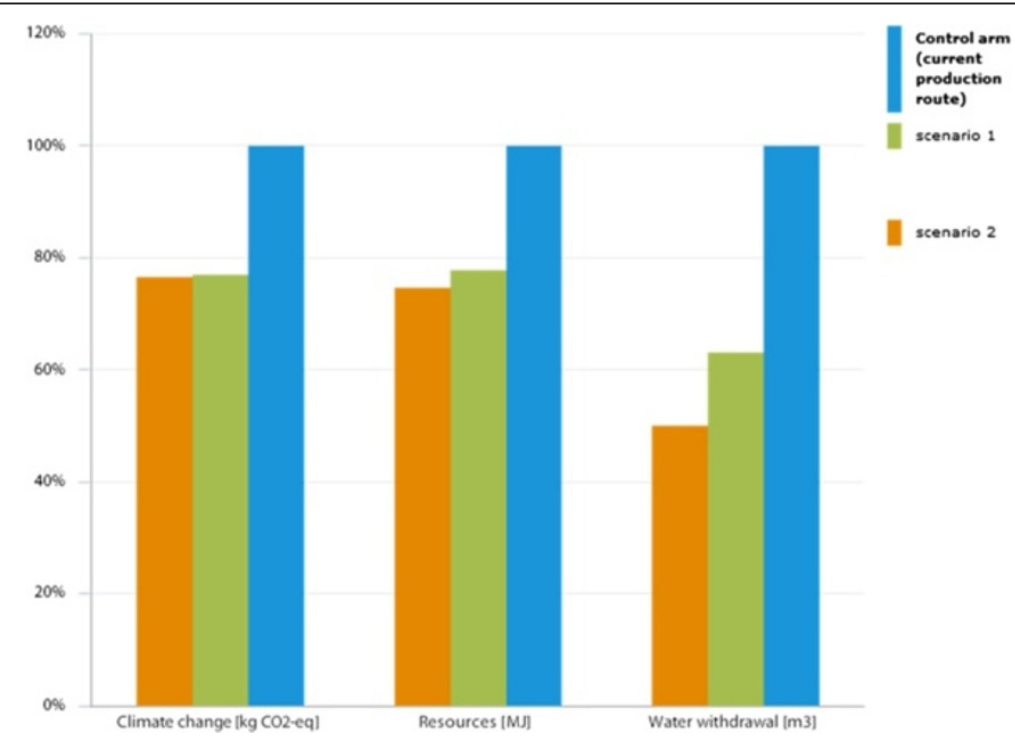

Figure 11 Environmental impacts of the scenarios compared to the baseline (merged life cycle stages). 
Table 3 AHP scores for the two reverse logistics scenarios, considering EOL environmental performance

\begin{tabular}{|c|c|c|c|c|c|c|c|c|c|c|c|}
\hline \multirow[t]{2}{*}{ AHP score } & \multicolumn{2}{|c|}{$\begin{array}{l}\text { Nonrenewable } \\
\text { energy }\end{array}$} & \multicolumn{2}{|c|}{ Climate change } & \multicolumn{2}{|c|}{$\begin{array}{l}\text { Fresh water } \\
\text { consumption }\end{array}$} & \multicolumn{2}{|c|}{ Recycling rate } & \multicolumn{2}{|c|}{ Total RL cost } & \multirow[t]{2}{*}{$\begin{array}{l}\text { Final } \\
\text { score }\end{array}$} \\
\hline & Weight & Score & Weight & Score & Weight & Score & Weight & Score & Weight & Score & \\
\hline Scenario 1 & 0.316 & 0.833 & 0.286 & 0.750 & 0.185 & 0.750 & 0.094 & 0.167 & 0.119 & 0.875 & 0.736 \\
\hline Scenario 2 & 0.316 & 0.167 & 0.286 & 0.250 & 0.185 & 0.250 & 0.094 & 0.833 & 0.119 & 0.125 & 0.264 \\
\hline
\end{tabular}

calculating a final score for every scenario in order to identify the best-fitting scenario for Raufoss. These scores are presented in Tables 3 and 4 for EOL and the whole life cycle, respectively.

\section{Results and discussions}

The obtained results in Figure 11 show a significant difference (of more than 20\%) between the baseline and scenarios 1 and 2 for climate change, resource consumption, and water withdrawal. This means that introducing recycled scrap is beneficial in terms of environmental impact reduction. Aluminum old scrap recycling is considered as less polluting than extracting virgin aluminum. This general point of view has been proved in this case study.

It is important to consider environmental impact of a reverse logistics network for its design. If only reverse logistics cost was considered as the decision criterion, scenario 1 would have been the best scenario. Nevertheless, considering environmental impact shows that scenario 2 is more beneficial. Scenario 2 has better environmental impact for the whole life cycle of the FLCA.

According to the results obtained and shown in Table 4, scenario 2 has a higher score and thus is the best-fitting scenario for the FLCA. This is in contradiction with the results obtained comparing only the environmental performance of the two scenarios for the EOL phase. Considering only the EOL environmental impact, scenario 1 received a final score of 0.736 , while scenario 2 received a score of 0.264 . Considering these results, scenario 1 is by far the best scenario and should thus be chosen for the reverse logistics network. Nevertheless, when considering the environmental impact for the entire life cycle, scenario 1 received a final score of 0.301 , while scenario 2 received a final score of 0.699 . Scenario 2 is in this case the best scenario and should be chosen. The total cost of the reverse logistics network and the recycling rate do not change. But the environmental performance changes when considering either one phase or the entire life cycle. This proves that the impact of the reverse logistics network on the whole life cycle of the product should be considered and not only for the EOL phase. In other words, the design of the reverse logistics network should take into consideration the forward supply chain in order to ensure a better performance for the entire chain (forward and reverse supply chain).

Table 4 AHP scores for the two reverse logistics scenarios, considering environmental performance for whole life cycle

\begin{tabular}{|c|c|c|c|c|c|c|c|c|c|c|c|}
\hline \multirow[t]{2}{*}{ AHP score } & \multicolumn{2}{|c|}{$\begin{array}{l}\text { Nonrenewable } \\
\text { energy }\end{array}$} & \multicolumn{2}{|c|}{ Climate change } & \multicolumn{2}{|c|}{$\begin{array}{l}\text { Fresh water } \\
\text { consumption }\end{array}$} & \multicolumn{2}{|c|}{ Recycling rate } & \multicolumn{2}{|c|}{ Total RL cost } & \multirow[t]{2}{*}{$\begin{array}{l}\text { Final } \\
\text { score }\end{array}$} \\
\hline & Weight & Score & Weight & Score & Weight & Score & Weight & Score & Weight & Score & \\
\hline Scenario 1 & 0.316 & 0.250 & 0.286 & 0.250 & 0.185 & 0.167 & 0.094 & 0.167 & 0.119 & 0.875 & 0.301 \\
\hline Scenario 2 & 0.316 & 0.750 & 0.286 & 0.750 & 0.185 & 0.833 & 0.094 & 0.833 & 0.119 & 0.125 & 0.699 \\
\hline
\end{tabular}




\section{Conclusion and perspectives}

In this paper, a method for designing a reverse logistics network was presented. It was the basis for the design of a reverse logistics and development of a plug-in. Both were used to design the reverse logistics network for the left front control arm for Raufoss Technology within the European project, SuPLight. The case study validated the method as well as the plug-in developed. They are both designed based on industrial needs. The AHP method was used to compare different reverse logistics scenarios. The aim of the proposed method is to design a reverse logistics network while taking into consideration all possible recovery activities, the possibility of having other partners in the network, and its environmental impact. The results obtained validate the necessity to consider other criteria than cost when designing a reverse logistics network. The results also show the necessity of considering the environmental impact of the reverse logistics network for the whole product life cycle.

The developed method and plug-in are based on human intervention and thus cannot be fully automated. Future works will focus on integrating a closed-loop supply chain approach which might offer several advantages in terms of improving the performance of the whole network and not only the RL network [35].

Competing interests

The authors declare that they have no competing interests.

Authors' contributions

JD carried out the literature review and case study. JD and JLD developed the reverse logistics network design methodology and drafted the manuscript. DP developed the plug-in. JLD and BE supervised the work. All authors read and approved the final manuscript.

\section{Acknowledgements \\ The authors would like to acknowledge the European Commission and the Picardie French Region for their financial support through the SuPLight FP7 Project (grant agreement no. 263302). They also wish to express their gratitude and appreciation to all the project partners for their contribution during the development of various ideas and concepts presented in this paper.}

Received: 31 July 2014 Accepted: 22 September 2014

Published online: 18 October 2014

References

1. Carter, CR, Ellram, LM: Reverse logistics: a review of the literature and framework for future investigation. J. Bus. Logist. 19(1), 85-102 (1998)

2. Ferrer, G, Ayres, R: The impact of remanufacturing in the economy. Ecol. Econ. 32(3), 413-29 (2000)

3. Castell, A, Clift, R, France, C: Extended producer responsibility policy in the European Union-a horse or a camel? J. Ind. Ecol. 8(1-2), 4-7 (2004)

4. Ravi, V, Shankar, R: Analysis of interactions among the barriers of reverse logistics. Technol. Forecast. Soc. Chang. 72(8), 1011-29 (2005)

5. Toffel, MW: The growing strategic importance of end-of-life product management. Calif. Manag. Rev. 45(3), 102-129 (2003)

6. DAS, SK, Yin, W: The worldwide aluminum economy: the current state of the industry. JOM. 59(11), 57-63 (2007)

7. Östlin, J, Sundin, E, Björkman, M: Importance of closed-loop supply chain relationships for product remanufacturing. Int. J. Prod. Econ. 115(2), 336-348 (2008)

8. Sundin, E, Dunbäck, O: Reverse logistics challenges in remanufacturing of automotive mechatronic devices. J. Remanufacturing. 3, 2 (2013)

9. Amini, MM, Retzlaff-Roberts, D, Bienstock, CC: Designing a reverse logistics operation for short cycle time repair services. Int. J. Prod. Econ. 96(3), 367-380 (2005)

10. Rogers, DS, Tibben-Lembke, RS: Going Backwards: Reverse Logistics Trends and Practices. RLEC Press, Pittsburgh (1999)

11. Mitra, S: Revenue management for remanufactured products. Omega. 35(5), 553-562 (2007)

12. Stock, J, Speh, T, Shear, H: Many happy (product) returns. Harv. Bus. Rev. 80(7), 16-8 (2002)

13. Fleischmann, M, van Wassenhove, LN, van Nunen, JAEE, van der Laan, E, Dekker, R, Bloemhof-Ruwaard, JM: Quantitative models for reverse logistics: a review. Eur. J. Oper. Res. 103(1), 1-17 (1997)

14. El Korchi, A, Millet, D: Conditions of emergence of OEM's reverse supply chains. J. Remanufacturing. 4, 3 (2014)

15. SuPLight: Document Deliverable 1.5: SuPLight Application Scenarios. SuPLight, EU FP7 Project, N²63302, (2012). http://cordis.europa.eu/project/rcn/99059_en.html

16. Stock, J: Product Returns/Reverse Logistics on Warehousing. WERC, IL, Oak Brook (2004) 
17. Ramezani, R, Bashiri, M, Tavakkoli-Moghaddam, R: A new multi-objective stochastic model for a forward/reverse logistic network design with responsiveness and quality level. Appl. Math. Model. 37(1-2), 328-344 (2013)

18. Min, H, Ko, CS, Ko, HJ: The spatial and temporal consolidation of returned products in a closed-loop supply chain network. Comput. Ind. Eng. 51(2), 309-320 (2006)

19. Üster, H, Easwaran, $G$, Akçali, E, Çetinkaya, S: Benders decomposition with alternative multiple cuts for a multi-product closed-loop supply chain network design model. Nav. Res. Logist. 54(8), 890-907 (2007)

20. Listes, O, Dekker, R: A stochastic approach to a case study for product recovery network design. Eur. J. Oper. Res. 160(1), 268-287 (2005)

21. Demirel, $\mathrm{ON}$, Gökçen, H: A mixed-integer programming model for remanufacturing in reverse logistics environment. Int. J. Adv. Manuf. Technol. 39(11-12), 1197-1206 (2008)

22. Pishvaee, MR, Kianfar, K, Karimi, B: Reverse logistics network design using simulated annealing. Int. J. Adv. Manuf. Technol. 47, 269-281 (2010)

23. Du, F, Evans, GW: A bi-objective reverse logistics network analysis for post-sale service. Comput. Oper. Res. 35(8), 2617-2634 (2008)

24. Zhou, Y, Wang, S: Generic model of reverse logistics network design. J. Transport. Syst. Eng. Inform. Tech. $8(3), 71-78$ (2008)

25. Lee, D-H, Dong, M: Dynamic network design for reverse logistics operations under uncertainty. Transport. Res. E Logist. Transport. Rev. 45(1), 61-71 (2009)

26. Lambert, S, Riopel, D, Abdul-Kader, W: A reverse logistics decisions conceptual framework. Comput. Ind. Eng. 61(3), 561-581 (2011)

27. Cardoso, SR, Barbosa-Póvoa, APFD, Relvas, S: Design and planning of supply chains with integration of reverse logistics activities under demand uncertainty. Eur. J. Oper. Res. 226(3), 436-451 (2013)

28. Wang, HF, Hsu, HW: A closed-loop logistic model with a spanning-tree based genetic algorithm. Comput. Oper. Res. 37(2), 376-389 (2010)

29. Chen, YJ: Structured methodology for supplier selection and evaluation in a supply chain. Inf. Sci. 181(9-1), 1651-1670 (2011)

30. Van der Rhee, B, Verma, R, Plaschka, G: Understanding trade-offs in the supplier selection process: the role of flexibility, delivery, and value-added services/support. Int. J. Prod. Econ. 120(1), 30-41 (2009)

31. Saaty, TL: The Analytic Hierarchy Process. McGraw- Hill, New York (1980)

32. Liu F-H, F, Hai, HL: The voting analytic hierarchy process method for selecting supplier. Int. J. Prod. Econ. 97(3), 308-317 (2005)

33. SuPlight, Deliverable 4.3: LCA/LCC Tools for Lightweight Solutions. SuPLight, EU FP7 Project, N²63302, (2013)

34. SuPLight, Deliverable 3.2: Generic Framework for Simulation-Based Optimization. SuPLight, EU FP7 Project, $N^{\circ} 263302,(2012)$

35. MA Asif, F, Bianchi, C, Rashid, A, Mihai Nicolescu, C: Performance analysis of the closed loop supply chain J. Remanufacturing. 2, 4 (2012)

doi:10.1186/s13243-014-0007-y

Cite this article as: Daaboul et al:: Reverse logistics network design: a holistic life cycle approach. Journal of Remanufacturing 2014 4:7.

\section{Submit your manuscript to a SpringerOpen ${ }^{\circ}$ journal and benefit from:}

- Convenient online submission

Rigorous peer review

- Immediate publication on acceptance

- Open access: articles freely available online

- High visibility within the field

Retaining the copyright to your article

Submit your next manuscript at $\boldsymbol{~ s p r i n g e r o p e n . c o m ~}$ 